\title{
Selection Approaches in High-Elevation Coastal Douglas-fir in The Presence of GxE Interactions
}

\author{
By M. StoenR ${ }^{1,3)}$, J. Woods ${ }^{2)}$ and A. YANChUK ${ }^{1)}$
}

(Received $18^{\text {th }}$ May 2010)

\begin{abstract}
Regeneration obligations in British Columbia for highelevation coastal sites requires a secure seed supply of quality seed in coastal Douglas-fir (Pseudotsuga menziesii (Mirb.) Franco). Consequently, a seed orchard is under development to supply seed after genetic testing and selection. For this purpose, 55 coastal Douglas-fir families were field-tested for 11 years on two contrasting high-elevation sites to examine differential growth performance and tolerance to cold conditions. Although heritabilities for growth on both sites were moderate at age 11 , the higher elevation colder site had substantially slower growth and over $90 \%$ of the trees exhibited some form of cold damage to foliage, branches and stems; however, variation in this damage was not significant at the family level. Combined site analysis revealed a highly significant genotype by environment (GxE) component in height that could not be removed or reduced by using site-specific error variances or spatial analysis (i.e., GxE was primarily due to rank changes of families across the two sites). This was also reflected by a drop in heritability estimates obtained from the combined site analyses. In the presence of this type of $\mathrm{GxE}$, independent culling, considering height a separate trait on each site, was employed to identify parents that were at a threshold breeding value of $5 \%$ or greater in growth superiority on both sites. Average breeding values for the selected parents, based on a combined site analysis, were around $5 \%$ above the trial mean for height at age 11. The use of independent culling, for situations where accurate genetic parameters are difficult to obtain, should be considered a practical alternative to more complex and error prone methods of selection.
\end{abstract}

Key words: independent culling, spatial analysis, breeding value, Pseudotsuga menziesii.

\section{Introduction}

Successful forest regeneration on high-elevation sites in coastal British Columbia (BC) continues to be a challenge. As the remaining accessible valley bottom areas are harvested, logging is progressing to higher elevations, and seed cone crops are very infrequent in high elevation coastal Douglas-fir (Pseudotsuga menziesii (Mirb.) Franco) stands. In anticipation of future seed needs in these areas, and to ascertain a more consistent seed supply, a seed orchard was established in 1972 with untested parents targeting the $700 \mathrm{~m}$ to $1200 \mathrm{~m}$ elevation band in coastal BC. In order to increase the

\footnotetext{
1) Research Branch, Ministry of Forests and Range, Victoria BC.

2) Select Seed Company, Duncan, BC.

$\left.{ }^{3}\right)$ Corresponding Author: Michael StOEHR.

727 Fisgard St., Victoria, BC, V8W 9C2, Canada. E-Mail: Michael.Stoehr@gov.bc.ca
}

genetic value of seed being obtained from this orchard, in 1997 two progeny tests were established in the CWHvm2 zone (Coastal Western Hemlock very moist '2' zone located between 650-1000 m elevation) (GREEN and KLINKA, 1994) with the purpose of obtaining breeding values for parents in the high-elevation coastal Douglasfir seed orchard. Based on the initial analysis of individual seedling heights taken in 2006 (i.e., age 11 from seed), a large genotype by environment interaction (GxE) effect was observed between these two test sites. Ideally, in the presence of large enough GxE, more than one seed supply zone should be identified (e.g., two separate seed orchards); however, the annual seed need is too low for managing separate breeding populations or orchards. To manage the coastal high elevation band as one seed supply zone, we applied BuRDON's (1979) general concept of a single trait (height in this study) being considered a separate trait on each site. Typically then, index selection would be applied to these two traits; however, independent culling can also be utilized as a means to select parents that performed well on both sites. Moreover, the application of independent culling is simpler as no additional trait weightings (over what the site heritabilities contribute) are required to attain some desired level of gain. Its general performance, from both theoretical and experimental results (e.g., CAMPO and RoDGRIGUEZ, 1986; VILLANUEVA and KENNEDY, 1993), has in many cases been shown to be as good as index selection, and may have superior properties particularly with respect to variance of response (SANCHEZ et al., 2008). This may be particularly important if the genetic covariances are poorly estimated, which is typical with a relatively small number of families in the test population. However, with independent culling there is an expected genetic penalty to be paid (XIE, 2003) by 'ignoring' GxE in such a manner (e.g., not including the genetic covariance in the determination of the breeding values (BV)), and the average BV of the selected parents estimated across sites is typically lower than the average BV estimated for each site, since some of the highest ranked parents on individual sites are culled. Of course, this 'genetic penalty' and the differences between classical index selection and independent culling becomes less as the genetic correlation becomes more positive (or less antagonistic).

The advantages of accounting for spatial variation in forest genetic tests has been recognized for some time now (e.g., Magnussen, 1990; Fu et al., 1999). More recently, several workers reported an increase in estimated heritabilities and/or improved precision of genetic parameters by partitioning the random error variance into a two dimensional, auto-correlated spatial compo- 
nent and a non-spatially dependent (independent) error (e.g., Costa e Silva et al., 2001; DutKowski et al., 2002, 2006; YE and JAYAWICKRAMA, 2008). This autoregressive model, denoted as AR1xAR1 (CuLLIS and GleESON, 1991; GiLmour et al., 1997), often leads to a reduction in experimental error variance, resulting in a more efficient statistical model and more accurate genetic parameters.

Here we apply several analytical methods to reduce the uncontrolled experimental error variance by first modeling separate test site error variances, and secondly, applying spatial analyses in combination with independent culling to attempt to maximize genetic gain in a relatively small test population, where $\mathrm{GxE}$ was important and economic and operational restrictions will not allow for more than one production population.

\section{Material and Methods}

\section{Test Establishment and Trait Measurement}

Polymix crosses were made on 55 of 70 parents growing in the untested high elevation seed orchard (Orchard 116) managed by Canadian Forest Product Ltd. (CANFOR), located at Sechelt, BC $\left(49^{\circ} 26^{\prime} 56^{\prime \prime N}\right.$, $123^{\circ} 43$ ' 13 ” W). To avoid selfing, two sets of pollen mixes of 11 and 13 pollen donors (selected from the orchard based on pollen availability) were applied to two groups of orchard females. The 55 pollinated orchard parents originated from elevations ranging from $457 \mathrm{~m}$ to 1006 $\mathrm{m}$ with an average elevation of $662 \mathrm{~m}$. Test seedlings were grown in a standard peat-vermiculite mix in family blocks at Cowichan Lake Research Station in 1996 in PSB615B styroblock containers. Seedlings were outplanted in 1997 on two sites, Mt. Cain (MC) $\left(50^{\circ} 11^{\prime} 53^{\prime} \mathrm{N}\right.$, $\left.126^{\circ} 20^{\prime} 16^{\prime \prime} \mathrm{W}, 1075 \mathrm{~m}\right)$ and Sutton Creek (SC) $\left(50^{\circ} 1\right.$ '66”N $\left.126^{\circ} 15^{\prime} 12^{\prime \prime} \mathrm{W}, 760 \mathrm{~m}\right)$, on northern Vancouver Island in two randomized complete block designs with eight blocks and four single (non-contiguous) tree plots/block/family. Spacing was $3 \mathrm{~m} \times 3 \mathrm{~m}$ on $\mathrm{MC}$ and $2.5 \mathrm{~m}$ by $2.5 \mathrm{~m}$ on SC. Heights $(\mathrm{cm})$ and diameter $(\mathrm{mm})$ at breast height $(\sim 130 \mathrm{~cm})$ were measured at the end of the growing season of 2006 (at age 11 from seed). However, only heights were considered in the analysis. Mechanical weeding and woody brush removal was done in 2003.

Due to observed stem and form damage caused by winter desiccation of exposed tree tops, stem form and health codes, assigned in 2006 to each tree, were defined as:

„1“) Top and mid section (30\%-50\% of total stem length) defoliated and dead with broken branches.

„2“) Top (10\%-20\%) defoliated and dead with broken branches.

„3“) Top (10\%-20\%) defoliated and dead, but no broken branches.

"4“) mid section (20\%-40\%) defoliated with broken branches, but top alive.

„5“) mid-section only defoliated (20\%-40\%), no broken branches, but top alive.

„6“) No damage and no health issues observed.

\section{Statistical Analysis and Genetic Parameter Calculations}

A family model was used to generate genetic parameters and parental breeding values (BV) for tree height for the purpose of roughing the seed orchard (i.e., backward selections). All analyses were conducted using ASREML (GILMOUR et al., 2006) which uses an average information (AI) restricted maximum likelihood (REML) estimation. The following linear mixed model was used:

\section{$\boldsymbol{Y}=\boldsymbol{X} \boldsymbol{\beta}+\boldsymbol{Z} \boldsymbol{v}+\boldsymbol{e}$}

where $\boldsymbol{Y}$ is the $\mathrm{n} \times 1$ vector of observed values (e.g. tree height and tree form), $\boldsymbol{\beta}$ is the unknown vector of fixed effects (in this case only the overall mean) with a known design matrix $\boldsymbol{X}, \boldsymbol{v}$ is an unknown vector of random effects (all other effects including the error) with known design matrix $\boldsymbol{Z}$ and $\boldsymbol{e}$ is a vector of random deviations. All random effects are assumed to be independent and normally distributed with mean zero with the following variance matrix:

$$
\sim \mathrm{N}\left[\begin{array}{l}
v \\
e
\end{array}\right] \sim \mathrm{N}\left(\left[\begin{array}{l}
0 \\
0
\end{array}\right],\left[\begin{array}{ll}
G & 0 \\
0 & R
\end{array}\right]\right)
$$

where $\boldsymbol{G}=\sigma_{s}^{2} I_{n s} \oplus \sigma_{b . s}^{2} I_{n b . s} \oplus \sigma_{f}^{2} I_{n f} \oplus \sigma_{s . f}^{2} I_{n s . f}$.

The term $I_{n}$ represents an identity matrix of the required dimension and $\oplus$ is the direct matrix sum.

In Model 1 (M1, the base model) $\boldsymbol{R}=\sigma_{e}^{2} I_{n}$ so that

$$
\operatorname{var}\left(\begin{array}{c}
s \\
b . s \\
f \\
s . f \\
e
\end{array}\right)=\left[\begin{array}{ccccc}
\sigma_{s}^{2} I_{n s} & 0 & 0 & 0 & 0 \\
0 & \sigma_{b . s}^{2} I_{n b . s} & 0 & 0 & 0 \\
0 & 0 & \sigma_{f}^{2} I_{n f} & 0 & 0 \\
0 & 0 & 0 & \sigma_{s . f}^{2} I_{n s . f} & 0 \\
0 & 0 & 0 & 0 & \sigma_{e}^{2} I_{n}
\end{array}\right]
$$

In Model 2 (M2), non-homogeneous error variances $(e)$ across the two plantation sites were accommodated and $\boldsymbol{R}$ was replaced by $\boldsymbol{R}_{2}$, where

$$
\boldsymbol{R}_{2}=\left[\begin{array}{cc}
\sigma_{e 1}^{2} I_{n 1} & 0 \\
0 & \sigma_{e 2}^{2} I_{n 2}
\end{array}\right],
$$

with numerical subscripts referring to sites 1 and 2 .

In Model 3 (M3), vector $\boldsymbol{e}$ was partitioned into spatially correlated and spatially independent residual vectors $\boldsymbol{e}=\boldsymbol{\xi}+\boldsymbol{\eta})$. Here we applied a two-dimensional first order autoregressive model (AR1 x AR1) (CULLIS and GLEESON, $1991)$ to the spatial 'trend' $\xi$, yielding a variance matrix of $\operatorname{Var}(\xi)=\sigma_{\xi}^{2} \boldsymbol{\Sigma}_{\boldsymbol{c}}\left(\boldsymbol{\rho}_{\boldsymbol{c}}\right) \otimes \boldsymbol{\Sigma}_{\boldsymbol{r}}\left(\boldsymbol{\rho}_{\boldsymbol{r}}\right)=$ where $\boldsymbol{\Sigma}_{\boldsymbol{c}}\left(\boldsymbol{\rho}_{\boldsymbol{c}}\right)$ and $\boldsymbol{\Sigma}_{\boldsymbol{c}}\left(\boldsymbol{\rho}_{\boldsymbol{c}}\right)$ are the usual $c \times c$ and $r \times r$ correlation matrices of an AR1 process for the columns and rows, and $\otimes$ is the direct (Kronecker) product. The variance of the spatially independent error is $\sigma^{2}{ }_{\eta} I_{n} \sigma$, so $\boldsymbol{R}_{3}=\operatorname{Var}(\boldsymbol{e})=\sigma_{\xi}^{2} \boldsymbol{\Sigma}_{\boldsymbol{c}}\left(\boldsymbol{\rho}_{\boldsymbol{c}}\right) \otimes$ $\boldsymbol{\Sigma}_{\boldsymbol{r}}\left(\boldsymbol{\rho}_{\boldsymbol{r}}\right)+\sigma_{\eta}^{2} I_{n}$. M1 and M3 were applied at the single-site level as well as across sites (combined site analysis).

Model superiority was evaluated using a log likelihood test (LRT) (DuTKOwski et al., 2006):

$$
\Lambda=2\left[\log L_{M 1}-\log L_{M 2}\right] \text { or } \Lambda=2\left[\log L_{M 1}-\log L_{M 3}\right]
$$

which has, under certain regularity conditions, an underlying $\chi^{2}$ distribution with degrees of freedom equal to the number of additional parameters (over and above M1) estimated in M2 and M3. 
Estimates of variance components were used to calculate individual tree heritability $\left(h_{i}^{2}\right)$.

$$
h_{i}^{2}=\sigma_{a}^{2} / \sigma_{p}^{2}=4 \sigma_{f}^{2} /\left(\sigma_{f}^{2}+\sigma_{s . f}^{2}+\sigma_{e}^{2}\right)
$$

$\sigma_{a}^{2}$ and $\sigma_{p}^{2}$ are the additive genetic and phenotypic variance and $\sigma_{f}^{2}, \sigma_{s . f}^{2}$, are the variance components due to family, family $x$ site interaction, (for combined by site analysis) and $\sigma_{e}^{2}$ is the experimental error mean square. For individual site analysis $\sigma_{s . f}^{2}$, is confounded with $\sigma_{f}^{2}$ and cannot be estimated (DIETERS et al., 1995). For combined site heritability calculations for M2 and M3, $\sigma_{e}^{2}$ was the average of the residual variance on each site.

Genotype by environment interactions $(\mathrm{GxE})$ were evaluated using the Type B genetic correlations $\left(r_{B}\right)$ (YAMADA, 1962; BuRDON, 1977) as:

$$
r_{B}=\sigma_{f}^{2} /\left(\sigma_{f}^{2}+\sigma_{\text {s.f }}^{2}\right)
$$

Standard errors for individual tree heritablities were approximated using the 'delta method' based on the Taylor expansion (LYNCH and WALSH, 1998) and directly obtained in the ASREML output (GILMOUR et al., 2006).

Best linear unbiased predictions (BLUPs) for each parents genetic merit were obtained for the two sites separately with the base model (M1) and the spatial model (M3), and all three models (M1-M3) for the combined site analysis. BLUPs for individual parents were converted to breeding values (BV) as follows:

\section{$B V=100 \cdot 2 \cdot \mathrm{BLUP} /$ site (or test) mean +2}

(XIE and YANCHUK, 2003)

As described above, we used independent culling (WHITE et al., 2007) with a threshold BV of 5 on both sites. The negative effect of GxE on selection outcome was evaluated by calculating the gain obtained using the BVs of the selected parents in the combined site analysis applying M1 to M3.

As damage and health problems were only observed on one site (MC), damage and health codes were subjected to single-site mixed model analysis (M1).

\section{Results and Discussion}

Survival was high in both test locations, despite the generally harsh climatic conditions at these relatively high elevation sites. However, substantial defoliation and severe damage to branches and stems were observed at the higher elevation MC site (Table 1). Climatic conditions on the two sites vary drastically with the climate at MC being much harsher. The damage on MC appeared to be due to desiccation during late winter or early spring when the trees foliage was not protected by snow cover, since damage occurred above a certain height, roughly at $1.5 \mathrm{~m}$ height. Although climate station data were not available, Climate BC (WANG et al., 2006) predicted the mean annual temperature at MC to be $5.4^{\circ}$, while at $\mathrm{SC}$ it was $7.0^{\circ}$; however, more importantly, the largest difference is for precipitation as snow (i.e., average annual snowfall of $829 \mathrm{~cm}$ vs. $474 \mathrm{~cm}$ for $\mathrm{MC}$ and SC, respectively). Although the two sites are located in the same BEC zone (CWHvm2), a zone characterized by a heavy snow pack and short growing seasons (GREEN and KLINKA, 1994), both sites are bordering the MHmm1 (mountain hemlock, moist maritime) zone, which is characterized as having a substantial snowpack which can often persist into July.

Mixed model analysis of variance (ANOVA) showed no genetic variation (i.e., variation due to families) in the damage assessment or health code score. Therefore, we considered damage as largely randomly distributed across families and due to local micro-environmental conditions that did not discriminate among genotypes (Table 2). As a consequence, damage, expressed as health code scores, was not used as a selection criterion. Furthermore, we observed no damage or other health concerns on SC (Table 1).

Tree heights at the end of 11 years from seed were much greater at SC than at MC. Individual- tree heritabilities for the two individual sites were high (Table 2). However, for the combined analysis individual tree heritabilities were much lower due to a strong GxE component, reflected in the low Type B genetic correlations $\left(\mathrm{r}_{\mathrm{B}}=0.21\right.$, Table 2$)$. In an attempt to reduce the magnitude of the GxE component, and to assess if the interaction was due to scale effects, site-specific residual error variances were modeled and applied in the analysis (M2). Although M2 was significantly better than the base model (M1), GxE was not reduced and $r_{B}$ did not increase (Table 2).

Spatial analysis further produced a model with significantly better fit and heritabilities increased in the individual site analysis from 0.33 and 0.32 to 0.36 for both MC and SC, respectively (Table 2). These increases are

Table 1. - Geographic site information and height means (standard deviations) and health codes for Douglas-fir seedlings growing on two high ele-

\begin{tabular}{|c|c|c|c|c|}
\hline Site & $\begin{array}{l}\text { No. of } \\
\text { Survivors }\end{array}$ & $\begin{array}{c}\text { Survival } \\
\%\end{array}$ & $\begin{array}{l}\text { Height } 11 \\
\quad(\mathrm{~cm})\end{array}$ & $\begin{array}{l}\text { Health } \\
\text { Code }\end{array}$ \\
\hline $\begin{array}{l}\text { Mt. Cain (MC) } \\
1043-1111 \mathrm{~m} \\
5091^{\prime} 53^{\prime \prime} \mathrm{N} \\
126^{\circ} 20^{\prime} 16^{\prime \prime} \mathrm{W}\end{array}$ & 1480 & 84 & $\begin{array}{l}290.4 \\
(67.2)\end{array}$ & 4.1 \\
\hline $\begin{array}{l}\text { Sutton Creek (SC) } \\
745-780 \mathrm{~m} \\
50^{\circ} 01^{\prime} 66^{\prime \prime} N \\
126^{\circ} 15^{\prime} 12^{\prime \prime} W\end{array}$ & 1577 & 90 & $\begin{array}{l}603.6 \\
(79.4)\end{array}$ & 6.0 \\
\hline
\end{tabular}
vation test sites on Vancouver Island. 
Table 2. - Estimates of variance components (VC) for health codes and height and its heritability and GxE interaction and autoregressive correlations for rows and columns in two high-elevation progeny tests sites of coastal Douglas-fir.

\begin{tabular}{|c|c|c|c|c|c|c|c|c|}
\hline \multirow{4}{*}{$\begin{array}{c}\text { Source of Variation/Model } \\
\text { Estimate }\end{array}$} & \multirow{4}{*}{$\begin{array}{l}\text { VC (Health Code) } \\
\text { Combined Sites }\end{array}$} & \multicolumn{7}{|c|}{ VC (Height) } \\
\hline & & \multicolumn{2}{|c|}{$\begin{array}{l}\text { Individual } \\
\text { Sites }\end{array}$} & & & \multicolumn{3}{|l|}{$\begin{array}{l}\text { Combined } \\
\text { Sites }\end{array}$} \\
\hline & & \multicolumn{2}{|c|}{$\mathrm{M1}^{1}$} & \multicolumn{2}{|l|}{ M3 } & \multirow[b]{2}{*}{ M1 } & \multirow[b]{2}{*}{ M2 } & \multirow[b]{2}{*}{ M3 } \\
\hline & & $\mathrm{MC}$ & SC & $\mathrm{MC}$ & SC & & & \\
\hline Site (S) & 1.8 & & & & & 48388 & 48381 & 45898 \\
\hline Rep/S & 0.02 & & & 0 & 264 & 455 & 454 & 161 \\
\hline $\operatorname{Rep} / M C$ & & 616 & & & & & & \\
\hline $\operatorname{Rep} / \mathrm{SC}$ & & & 296 & & & & & \\
\hline $\operatorname{Fam}(\mathbf{F})$ & 0 & 327 & 484 & 306 & 461 & 84 & 84 & 78 \\
\hline$S^{*} \mathrm{~F}$ & 0.01 & & & & & 318 & 318 & 299 \\
\hline $\operatorname{Rep} / 5^{*} \mathrm{~F}$ & & & & & & 0 & 0 & 0 \\
\hline Residual & 0.63 & & & 3128 & 4441 & 4656 & & \\
\hline Residual MC & & 3679 & & & & & 4679 & 3106 \\
\hline Spatial Residual MC & & & & 893 & & & & 873 \\
\hline \multirow[t]{2}{*}{ Spatial Residual SC } & & & & & 1075 & & & 1068 \\
\hline & & & & & Spatial & Correlations & & \\
\hline AR row $M C$ & & & & 0.90 & & & & 0.88 \\
\hline AR COl MC & & & & 0.92 & & & & 0.91 \\
\hline AR row $S C$ & & & & & 0.65 & & & 0.66 \\
\hline AR col SC & & & & & 0.44 & & & 0.45 \\
\hline $\log \mathrm{L}$ & -867 & -6860 & -7629 & -6804 & -7609 & -14533 & -14533 & -14420 \\
\hline$p>D(L R T)$ & & & & 0.000 & 0.000 & & ns & 0.000 \\
\hline$h_{i}^{2}(S E)$ & & 0.33 & 0.32 & 0.36 & 0.36 & 0.07 & 0.07 & 0.07 \\
\hline SE & & 0.08 & 0.08 & 0.08 & 0.08 & 0.06 & 0.06 & 0.06 \\
\hline$r_{B}$ & & & & & & 0.21 & 0.21 & 0.21 \\
\hline
\end{tabular}

${ }^{1}$ Models described in text.

in line with those observed by YE and JAYAWICKRAMA (2008) comparing spatial vs. non-spatial analysis for coastal Douglas-fir in the Pacific Northwest. However, spatial analysis resulted in only minute changes in heritability for the combined site analysis with no associated reduction in the standard error (Table 2, combined site analyses, M1 vs. M3). Furthermore, spatial analysis did not remove or reduce the magnitude of the $\mathrm{GxE}$ variance (Table 2), suggesting that this source of variation was due to rank changes in family performance. These rank changes are also presented in columns 1 and 3 of Table 3.

GxE interactions generally present a conundrum for tree breeders with respect to seed zone delineation and selection of parents to produce seeds for a single seed production unit (SHELBOURNe, 1972). By considering height growth on the two sites as different traits, and applying independent culling, we only selected families that performed well on both sites, and accepted the reduction in gains that would have been possible by selecting families that did well on individual sites. It was interesting that there was no significant differentiation among families for the winter damage score on MC, yet we detected substantial GxE in height growth performance across the two sites. Clearly, adaptive differences among families are present across the two sites, yet the damage event(s) on MC were not related to the genetic attributes affecting GxE. Winter desiccation was therefore determined by random micro-climate events around individual trees and these were severe enough to affect most Douglas-fir trees in the test.

Figure 1 shows the distribution of family BV for MC vs. SC. Only families with BVs above $4.5 \%$ on both sites were considered for selection. Six of the 55 tested families satisfied the selection criteria on both sites (Table 3, shaded). The average genetic gain in height of these six selections on $\mathrm{MC}$ was $14.2 \%$ and $8.7 \%$ on SC, a reduction of $39 \%$ and $27 \%$ respectively, if only the top performers on each site would have been selected.

To obtain BVs for the six selected families across all potential planting sites in the seed production unit, BLUP estimates from the combined site analysis using M1 to M3 were generated (Table 3). On average, all three models yielded similar BLUPS with standard errors of the BLUP estimates being only slightly smaller for M3 vs. M1 (i.e., 2.06 vs. 2.01, data not shown). The average gain of the selected parents across the seed production zone is $5 \%$, which was only $0.8 \%$ lower than if the top six parents would have been selected based on the combined site (spatial) BLUPs. Therefore, the use of independent culling on each site, over the combined BLUP analyses, or more complicated selection index, was a an effective and simple way of making selections in this small population for our particular objective (i.e., identifying a set of parents in spite of relatively large GxE being present). 
Table 3. - Height breeding values (BV) for the six selected (shaded) and top 20 coastal Douglas-fir parents tested on two sites (MC and SC) applying several models (M1 to M3) for individual and combined site analyses.

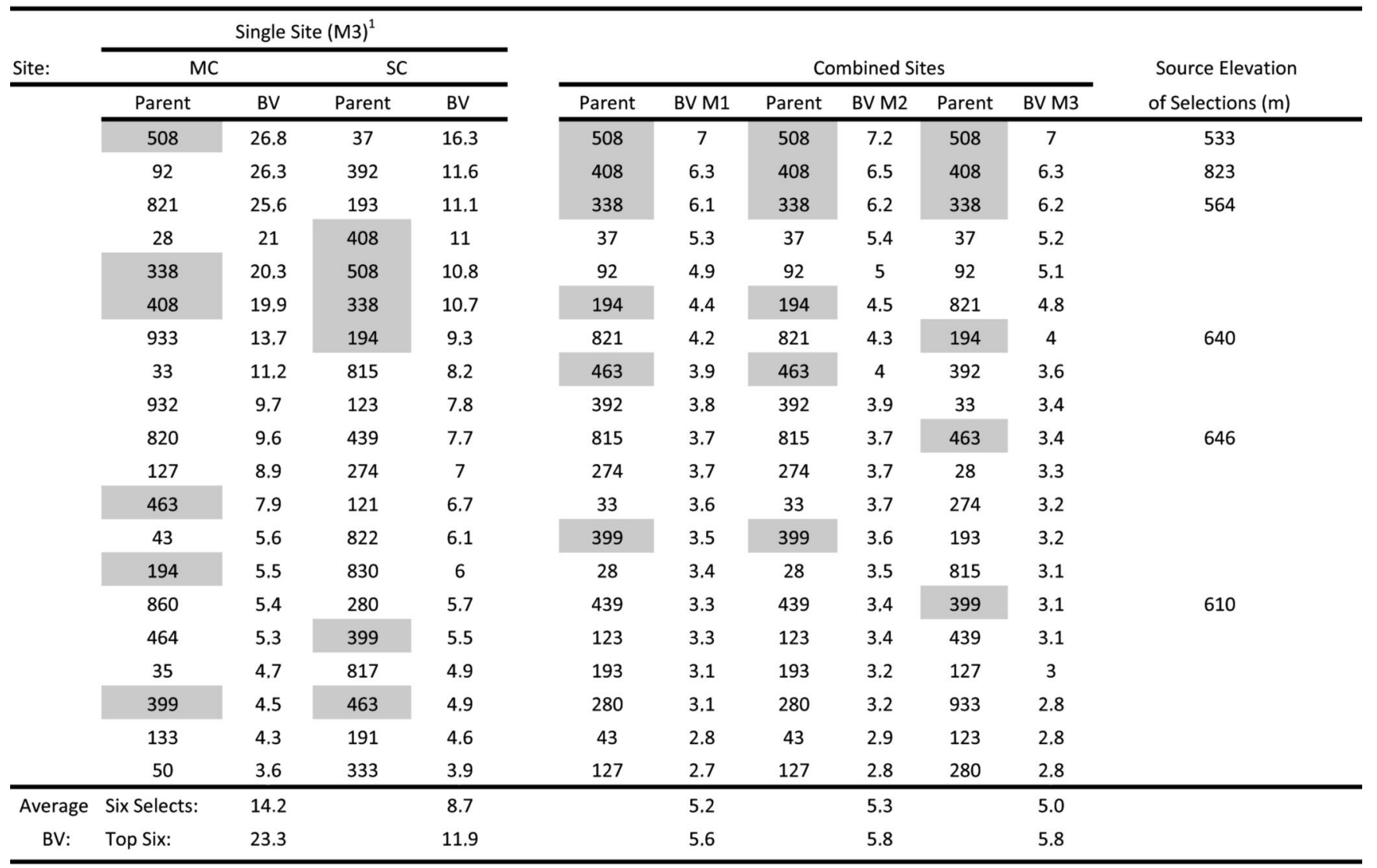

${ }^{1} \mathrm{M} 1$ to $\mathrm{M} 3$ refers to models described in text.

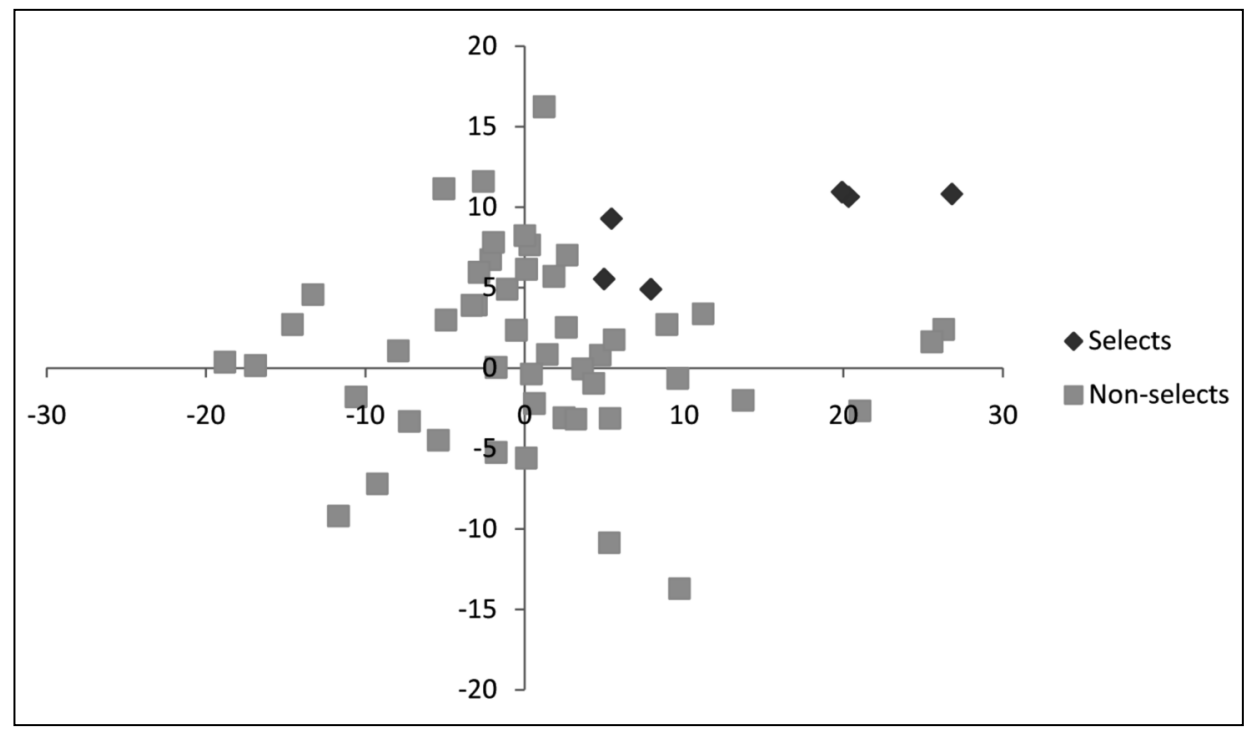

Figure 1. - Scatter plot of MC BVs (x-axis) vs. SC BV (y-axis) for each tested family. Black diamonds represent selected parents for high-elevation Douglas-fir seed orchard establishment.

In British Columbia we have a legal requirement of a minimum effective population size of $\mathrm{N}_{\mathrm{e}}=10$ for each seedlot (CHIEF Forester's STANDARDS, 2005). To satisfy this requirement, parents from other testing populations will be infused into this production population before seed can be registered for reforestation on Crown land. Nevertheless, this group of selections made using independent culling of parents that exhibit good growth potential and reasonable tolerance to cold or winter damage, are a good starting base population for additional high elevation Douglas-fir seed orchards in coastal B.C. 


\section{Conclusions}

Our goal was to attempt to select fast growing parents that were capable of good growth on productive and harsh, high-elevation sites. The approach of using independent culling is well known in plant and tree breeding, but is rarely applied to the same trait on different sites. Clearly, at SC height growth are a reflection of growth potential, while at MC growth is more of an indication of adaptation to a very harsh environment. The approach we chose for making selections in the presence of $\mathrm{GxE}$ resulted in the selection of parents that performed well on both sites (i.e., rather than 'specialists'), which in our opinion, is an operational and technically sound compromise for a small seed production unit that cannot justify the establishment of two separate breeding and/or production populations. Spatial analyses did not improve genetic parameter estimates drastically but always improved model fit, which in turn causes an increase in accuracy of test results and BV estimation.

\section{Acknowledgements}

PATTI BROWN, formerly of CANFOR Canada, was instrumental in setting up the tests and co-operated with obtaining funding from FRBC. The technical assistance of KEITH BIRD and LISA HAYTON throughout the testing period is much appreciated. The internal reviews of Peter OtT, Nick Ukrainetz and John Russell improved the manuscript drastically.

\section{Literature Cited}

BuRdon, R. D. (1977): Genetic correlation as a concept for studying genotype-environment interaction in forest tree breeding. Silvae Genet. 26: 168-175.

BuRDON, R. D. (1979): Generalisation of multi-trait selection indices using information from several sites. NZ J For Sci. 9(2): 145-152.

CAmpo, J. L. and C. Rodgriguez (1986): Experimental comparison of methods for simultaneous selection of two correlated traits in Tribolium. 2. Index selection and independent culling levels: a replicated single generation test. Genet. Sel. Evol. 18: 431-445.

Chief Forester's Standards for Seed Use (2005): B.C. Ministry of Forests, Victoria, BC. (http://www.for.gov.bc. ca/code/cfstandards/).

Costa e Silva, J., G. W. Dutkowski and A. R. Gilmour 2001): Analysis of early tree height in forest genetic trials is enhanced by including a spatially correlated residual. Can. J. for. Res. 31: 1887-1893.

Cullis, B. R. and A. C. Gleeson (1991): Spatial analysis of field experiments - an extension to two dimensions. Biometrics 47: 1449-1460.

Dieters, M. J., T. L. White and G. R. Hodge (1995): Genetic parameter estimates for volume from full-sib tests of slash pine (Pinus elliotti). Can. J. For. Res. 25: 1397-1408.

Dutkowski, G. W., J. Costa e Silva, A. R. Gilmour and G. A. LOPEz (2002): Spatial analysis methods for forest genetic trials. Can. J. for. Res. 32: 2201-2214.
Dutkowski, G. W., J. Costa E Silva, A. R. Gilmour, H. Wellendorf and A. Aguiar (2006): Spatial analysis enhances modelling of wide variety of traits in forest genetics trials. Can. J. For. Res. 36: 1851-1870.

Fu, Y. B., G. NAmKoOnG and A. D. YANChuK (1999): Spatial patterns of tree height variation in a series of Douglasfir progeny trials: implications for genetic testing. Can. J. For. Res. 29: 714-723.

Gilmour, A. R., B. R. Cullis and A. P. Verbyla (1997): Accounting for natural and extraneous variation in the analysis of field experiments. J. Agric. Biol. Environ. Stat. 2: 269-293.

Gilmour, A. R., B. J. Gogel, B. R. Cullis and R. ThompSON (2006): ASReml User Guide 2.0. VSN International Ltd., Hempstead, HP1 1ES, UK.

Green, R. N. and K. KLINKA (1994): A field guide to site identification and interpretation for the Vancouver Forest Region. Land Management Handbook 28, Res. Br., Ministry of Forests, Prov. of British Columbia. Crown Publications, pp. 101.

LYNCH, M. and B. WALSH (1998): Genetics and analysis of quantitative traits. Sinaauer Assoc., Sunderland, MA, USA. $980 \mathrm{pp}$.

Magnussen, S. (1990): Application and comparison of spatial models in analyzing tree-genetics field trials. Can. J. For. Res. 20: 536-547.

SANCHEZ, L., A., YANCHUK and J. N. KING (2008): Gametic models for multitrait selection schemes to study variance of response and drift under adverse genetic correlations. Tree Genet. Genom. 4: 201-212.

ShelBourne, C. J. A. (1972): Genotype-environment interaction: its study and implication in forest tree improvement. In: Proc. Of Joint Symposia for the Advancement of Forest Tree Breeding of the Genetics Subject group, IUFRO, and Sect. 5, Forest Trees, SABRO. Government For. Exp. Stn. of Japan, Tokyo, pp. B-1 I 1-28.

Villanueva, B. and B. W. KennedY (1993): Index versus tandem selection after repeated generations of selection. Theor. Appl. Genet. 85: 706-712.

Wang, T., A. Hamann, D. L. Spittlehouse and S. N. AITKEN (2006): Development of scale-free climate data for western Canada for use in resource management. Int. J. Climatology 26: 383-397.

White, T. L. , W. T. AdAms and D. B. Neale (2007): Forest Genetics. CABI Publishing, Cambridge, USA. 682 pp.

XIE, C.-Y. (2003): Genotype by environment interaction and its implications for genetic improvement of interior spruce in British Columbia. Can. J. For. Res. 33: 1635-1643.

XIE, C.-Y. and A. D. YANCHUK (2003): Breeding values of parental trees, genetic worth of seed orchard seedlots, and yields of improved stocks in British Columbia. WJAF 18(2): 88-100.

YAMADA, Y. (1962): Genotype by environment interaction and genetic correlation of the same trait under different environments. Jpn. J. Genet. 37: 498-509.

Ye, T. Z. and K. J. JaYAWICKRAMA (2008): Efficiency of using spatial analysis in first-generation coastal Douglas-fir progeny tests in the US Pacific Northwest. Tree Genet. Genomes 4(4): 677-692.

Herausgeber: Johann Heinrich von Thünen-Institut. Bundesforschungsinstitut für Ländliche Räume, Wald und Fischerei. Schriftleitung: Institut für Forstgenetik, Sieker Landstraße 2, D-22927 Großhansdorf

Verlag: J. D. Sauerländer's Verlag, Finkenhofstraße 21, D-60322 Frankfurt a. M. Anzeigenverwaltung: J. D. Sauerländer's Verlag, Frankfurt am Main.

Gesamtherstellung: PPPP Norbert Wege e.K., Gladenbach — Printed in Germany. 